\title{
Unintended Consequences of Agricultural Participation in Voluntary Carbon Markets: Their Nature and Avoidance
}

\author{
Minglu Wang $\left(\mathbb{D},{ }^{1}\right.$ Bruce McCarl $\mathbb{D}$, ${ }^{2}$ Hanlin Wei $\mathbb{D}^{3}$ and Layla Shiva $\mathbb{D}^{4}$ \\ ${ }^{1}$ School of Public Finance and Taxation, Southwestern University of Finance and Economics, Chengdu, China \\ ${ }^{2}$ Department of Agricultural Economics, Texas A\&M University, College Station, TX, USA \\ ${ }^{3}$ College of Economics and Management, China Agricultural University, Beijing, China \\ ${ }^{4}$ Department of Economics, Tehran Institute for Advanced Studies, Tehran, Iran
}

Correspondence should be addressed to Bruce McCarl; brucemccarl@gmail.com

Received 14 May 2021; Accepted 5 July 2021; Published 17 July 2021

Academic Editor: Baogui Xin

Copyright ( 2021 Minglu Wang et al. This is an open access article distributed under the Creative Commons Attribution License, which permits unrestricted use, distribution, and reproduction in any medium, provided the original work is properly cited.

\begin{abstract}
Greenhouse gas (GHG) trading markets have been widely discussed for climate change mitigation. However in implementation coverage has not been universal. Agriculture, despite being the source of nearly $25 \%$ of net emissions, has not commonly been capped. But it has been mentioned as voluntary source of net emission offsets. Such offsets could arise from action reducing GHG emissions, enhancing sequestration, or producing feedstocks for low emitting bioenergy replacements for fossil based energy. This could be harnessed by setting up voluntary carbon markets that producers could join at their discretion. However, such a scheme could have unintended consequences. We conduct theoretical and empirical analyses of a voluntary "carbon" market examining both intended and unintended effects. We find certain participation rules can stimulate rebound effects from emitters and suppress participation from sequestration and bioenergy producing entities. To overcome this we develop and simulate offset participation limitations that could preclude unintended consequences.
\end{abstract}

\section{Introduction}

Emission trading markets have been advanced as a mechanism reducing emissions in many settings including greenhouse gas (GHG) ones [1]. The Kyoto Protocol (KP) advocated trading markets and since then they have been prominently discussed in the climate change mitigation dialogue with a number of implementations. Such markets conceptually cap the emissions of an entity and then facilitate trading between expensive and cheaper net emissions reducers [1]. Typically capped entities include electricity generators, petroleum refiners, and cement manufacturers all of which generally face high costs to achieve large emission reductions. Sectors such as agriculture and forestry have typically not been capped. However, a number of markets and market designs include provisions where capped entities can buy offsets from uncapped sectors. One way of allowing such sales involves setting up a voluntary carbon offset market in which uncapped producers could make offers to sell. The project-based clean development mechanism (CDM) provides an example of this and allows capped producers in industrialized countries to buy certified emission reduction credits from developing countries. Allowing sales through offsets complements cap and trade programs and can reduce abatement costs relative to a program without access to offsets in uncapped sectors [2].

Agriculture, forestry, and other land use activities have been estimated to have a $23 \%$ share of total global emissions in recent times and as such are a potential source of emissions reductions [3]. However, the agricultural sector has generally not been capped in GHG trading schemes but rather is often identified as an offset supplying sector [4]. Such offsets could be developed by adoption of agricultural actions that reduce GHG emissions, enhance carbon sequestration, or provide feedstocks for bioenergy that replace higher emitting fossil based energy [5]. Emission reducing possibilities include actions to lessen emissions from enteric fermentation, manure management, rice cultivation, 
fertilization, soil management, field burning, machinery operations, and avoided deforestation [5, 6]. Sequestration can be enhanced through deintensification of tillage, residue management, use of soil carbon enhancing crop rotations, cropland conversion to grasslands, improved grassland management, afforestation, reforestation, and restoration of degraded soils [6, 7]. Emissions also can be offset by replacing fossil fuels used in energy production with agriculturally produced feedstocks [8]. Sequestration strategies can also be price-competitive at low carbon prices as they are often complementary to current agricultural soil management practices but at higher carbon prices practices like bioenergy production and forestry can be more desirable as they yield larger net GHG emission reductions [9].

Thus there are three basic situations where a farmer might be able to sell offsets. These are as follows:

(1) A cap and trade system allows covered individuals to purchase offsets from outside of the program or enrolled region. For example, the California Rice Protocol allows use of rice methane emission reducing practices in or out of California to satisfy needed emission reductions by capped parties [10].

(2) A program places emission limits on certain entities (like power plants) but they are allowed to satisfy the limits by purchasing offsets from others. For example, this might have happened under the proposed Clean Power Plan (CPP) that may be revisited in the near term.

(3) An organization offers a program where producers can sign up to sell offsets based on shifts in practices. For example, the Verified Carbon Standard (VCS) functions outside of compliance markets and facilitates purchases by firms that want to be demonstrably "greener" [11]. In recent years, more and more private companies such as Indigo Carbon and Noris Marketplace are getting involved by aggregating carbon offsets and then selling them to interested parties in a voluntary marketplace setting. Voluntary programs require less implementation cost but conceptually lead to lower levels of offsets than do mandatory programs [12].

However, voluntary carbon markets suffer from substantial criticism regarding a large number of nonadditional offsets as a result of adverse selection. That problem stems from the fact that business as usual (BAU) emissions cannot be fully observed by regulators. To address this problem, baseline selection and manipulation have been extensively discussed regarding actions in the transportation [13], commercial building $[14,15]$, and forestry sectors [16]. In general there is a tradeoff between additionality and participation including payments to "good actors.". In such cases a generous baseline can lead to credits to preexisting practices generating nonadditional offsets and implicitly relaxes the emission cap in compliance markets while a stringent baseline would eliminate many nonadditional offsets but also suppress the incentive to opt in and perhaps cause preexisting users of mitigation practices to reverse such practices stimulating emissions and then join the program $[17,18]$. Carbon leakage is also a concern since most of current programs are regional and can displace traditional commodity production stimulating emission increase outside of the programs scope [19].

Participation by those in agriculture also raises challenges. Lichtenfeld [20] indicated that land managers were reluctant to enter the carbon market for three main reasons: high transactions and management costs, imperfect information, and a lack of institutional support. Also farmers have concern over the long term effectiveness of weed control methods that are key to use of limited tillage strategies [21]. On the other hand, emission reductions have measurement issues in cases due to potentially high measurement cost, need for sophisticated equipment, their nonpoint source nature, and variable levels across time, locations, and climate conditions. Because of these factors and eligibility restrictions, the actual level of GHG mitigation is far below what many expected at the time of formation of the Kyoto Protocol [22].

This investigates voluntary market design in an effort to evolve designs that better stimulate program participation and generate net emission reductions. Specifically, we conduct theoretical analysis and empirical simulations of the consequences of alternative voluntary market designs examining effects on net GHG emissions and possible market reactions that lead to unintended consequences.

The significance of this study is fourfold. First, we integrate agricultural emission control activities, sequestration, bioenergy production, and voluntary carbon market participation into a single framework for study. Second, our study explores use of performance baselines, which utilize predefined emissions thresholds for a class of activities, and it differs from many prior studies that focused on setting costly, adverse selection, nonadditional prone project-based baselines [23]. Also, the performance baseline under limited private cost information and an uncertain market environment has been found to reduce leakage $[15,24]$. Third, we use a baseline method in per unit participating, rate-based form instead of lump sum form which [25] argues is more realistic and responsive to external conditions. Fourth, since the credits are proportional to the output level, this may lead to unintended effects such as output expansion and emission increase $[25,26]$, but we introduce fairly simple constraints to limit unintended effects.

This study is organized as follows. Section 2 sets out a basic analytical model of participation and abatement decisions for a profit maximizing entity. Then analytical results are derived and they provide a basis for our empirical study. Section 3 describes an empirical test of our posed constraint effectiveness using an agricultural sector model. Section 4 discusses the simulation results. Section 5 concludes the paper.

\section{Theoretical Analysis}

In this section, a theoretical analysis will be conducted to investigate the effect of voluntary carbon crediting programs on net GHG emission reductions by examining cases for both emission reducers and sequestration enhancers. We 
evaluate the circumstances when net emission reductions are achieved and when unintended effects arise. This analytical model is elaborated in [27].

2.1. A No-Trading Base Scenario. A base scenario is set up to portray the situation in the absence of carbon payments. There we assume a producer can access two technologies producing a commodity but with different emissions consequences and costs (i.e., low and high emissions rice). The possibilities are the commonly used baseline strategy, $x_{1}$, and a more costly "net emission reducing" alternative, $x_{2}$. The producer maximizes profits by solving the following optimization problem where one of the two technologies are chosen:

$$
\begin{aligned}
& \operatorname{Max} \pi=\left(p x_{1}+p x_{2}\right)-x_{1} C_{1}\left(x_{1}\right)-x_{2} C_{2}\left(x_{2}\right), \\
& \text { s.t. } x_{1} x_{2}=0 \\
& \quad x_{1}, x_{2} \geq 0 .
\end{aligned}
$$

$p$ is the output price and $C_{i}\left(x_{i}\right)$ is the cost function for producing $x_{i}$. We assume either $x_{1}$ or $x_{2}$ is adopted but not both of them by imposing constraints (2) and (3). Additionally, we assume $C_{i}\left(x_{i}\right)$ is a linear increasing cost function of producing the quantity $x_{i}$ :

$$
C_{i}\left(x_{i}\right)=c_{i}+\mathrm{d} x_{i},
$$

where via this function $x_{1}$ production is cheaper than $x_{2}$ production since $x_{2}$ required one-time investment for technology upgrades. For simplicity we structure this so both alternatives costs increase at the positive rate $d$ as volume is expanded and both alternatives are initially profitable in the market $\left(c_{2}>c_{1}>0, p-c_{i}>0\right.$; and $\left.d>0\right)$.

If we use calculus to solve the choice problem we arrive at the base solution that only $x_{1}$ will be produced since $x_{1}$ is more cost-effective.

$$
\begin{aligned}
& x_{1}^{*}=\frac{p-c_{1}}{2 d}, \\
& x_{2}^{*}=0 .
\end{aligned}
$$

On the emissions side, we suppose net emissions rates $e_{i}$ for producing $x_{i}$ and $e_{1}>e_{2}$ so $x_{2}$ is net emissions reducing relative to $x_{1}$. We also will assume $e_{1}$ and $e_{2}$ are of the same sign so they are both either positive or negative. The total net emissions in the absence of a carbon market are

$$
E B^{*}=e_{1} x_{1}^{*}+e_{2} x_{2}^{*}=\frac{e_{1}\left(p-c_{1}\right)}{2 d},
$$

$E B^{*}$ is the total BAU net emissions, and $e_{1}$ is the per unit baseline performance standard that the market must do better than under the voluntary market. Note that $E B^{*}$ could be negative if $e_{1}$ is negative.

2.2. Adding in a Voluntary Carbon Market. Now we add carbon price into the model so that producers have an incentive to choose $x_{2}$ and reduce emissions (a choice we call opt in). In setting the model up we add a baseline standard per unit produced for the net emission level, $e^{b}$, to calculate the reduction of net emissions rate relative to the standard. We also assume payments are paid for the difference in net emissions. The resultant model is

$$
\begin{aligned}
\operatorname{Max} \pi= & \left(p x_{1}+p x_{2}\right)-x_{1} C_{1}\left(x_{1}\right)-x_{2} C_{2}\left(x_{2}\right) \\
& -M\left[x_{1}\left(e_{1}-e^{b}\right)+x_{2}\left(e_{2}-e^{b}\right)\right], \\
\text { s.t. } x_{1} x_{2} & =0, \\
x_{1}, x_{2} & \geq 0,
\end{aligned}
$$

where $M$ is the carbon price. We set $e^{b}=e_{1}$ since $x_{1}$ is adopted in the BAU without a carbon market and equation (7) becomes

$$
\begin{aligned}
\operatorname{Max} \pi= & \left(p x_{1}+p x_{2}\right)-x_{1} C_{1}\left(x_{1}\right)-x_{2} C_{2}\left(x_{2}\right) \\
& -M\left[x_{2}\left(e_{2}-e_{1}\right)\right] .
\end{aligned}
$$

From the equation, we see continuing to use $x_{1}$ yields no carbon market payments, while using $x_{2}$ results in a payment equaling $M x_{2}\left(e_{1}-e_{2}\right)$ but also a higher production cost. The optimal choice of $x$ in the voluntary market is $x_{1}$ for the carbon price below a threshold:

$$
\begin{aligned}
& x_{1, v}^{*}=\frac{p-c_{1}}{2 d}, \\
& x_{2, v}^{*}=0, \quad \text { when } M<\frac{c_{2}-c_{1}}{e_{1}-e_{2}},
\end{aligned}
$$

and the choice shifts to $x_{2}$ when the carbon price is above that threshold with the production level being

$$
\begin{aligned}
& x_{2, v}^{*}=\frac{p-c_{2}-M\left(e_{2}-e_{1}\right)}{2 d}, \\
& x_{1, v}^{*}=0, \quad \text { when } M>\frac{c_{2}-c_{1}}{e_{1}-e_{2}},
\end{aligned}
$$

and when $x_{2}$ is the choice the level of total net emissions is

$$
E_{v}^{*}=e_{1} x_{1, v}^{*}+e_{2} x_{2, v}^{*}=\frac{e_{2}\left[p-c_{2}-M\left(e_{2}-e_{1}\right)\right]}{2 d} \text {. }
$$

Then comparing with total BAU net emissions we get

$$
\begin{aligned}
E_{v}^{*}-E B^{*}= & e_{2} x_{2, v}^{*}-e_{1} x_{1}^{*}=\frac{e_{2}\left[p-c_{2}-M\left(e_{2}-e_{1}\right)\right]}{2 d} \\
& -\frac{e_{1}\left(p-c_{1}\right)}{2 d} .
\end{aligned}
$$

In order to simplify the emission difference expression, we substitute $c_{2}=c_{1}+\Delta c$ and $e_{1}=e_{2}+\Delta e$. Note that $\Delta c>0$ and $\Delta e>0$.

$$
\begin{aligned}
E_{v}^{*}-E B^{*}= & e_{2} x_{2, v}^{*}-\left(e_{2}+\Delta e\right) x_{1}^{*}=\frac{e_{2}\left(p-c_{1}-\Delta c+\Delta e M\right)}{2 d} \\
& -\frac{\left(e_{2}+\Delta e\right)\left(p-c_{1}\right)}{2 d},
\end{aligned}
$$


and by simplifying we get

$$
\begin{aligned}
E_{v}^{*}-E B^{*} & =e_{2}\left(x_{2, v}^{*}-x_{1}^{*}\right)-\Delta e x_{1}^{*} \\
& =\frac{\Delta e\left(p-c_{1}\right)-e_{2} \Delta c+\Delta e M e_{2}}{2 d} .
\end{aligned}
$$

Note that all the items in equation (16) are positive except $e_{2}$ which can be positive (when we are paying for reducing emissions) or negative (when we are paying for enhancing sequestration). Now, let us explore whether the program may cause increased net emissions. To do this, we consider two cases where (1) net emissions are positive and are being reduced $\left(e_{1}, e_{2}>0\right.$, and $e_{1}>e_{2}$ so $\left.\Delta e>0\right)$ and (2) net emissions are negative implying sequestration or biofuel offsets that are becoming more negative when $x_{2}$ is used $\left(e_{1}, e_{2}<0\right.$, and as above $e_{1}>e_{2}$ so $\left.\Delta e>0\right)$.

In the case of positive emitting strategies, note the last term $+\Delta e \mathrm{Me}_{2}$ has all positive components and can cause an emissions increase that grows as the carbon price $(M)$ does while the other terms $\left(\Delta e\left(p-c_{1}\right)-e_{2} \Delta c\right)$ are independent of the carbon price. Now, we solve for the size of $M$ when alternative net emissions exceed the BAU net emissions. We find

$$
E_{v}^{*}-E B^{*}>0, \quad \text { when } M>\frac{c_{2}-c_{1}}{e_{1}-e_{2}}+\frac{p-c_{1}}{e_{2}} .
$$

Here we find a rebound effect [28] where the carbon price stimulates more $x_{2}$ production than in the baseline offsetting the gain from lower per unit emissions. An illustration of such an effect is that if per acre rice emission reductions were possible, the incentive may cause the acreage of "low emitting" rice $\left(x_{2, v}^{*}\right)$ to expand substantially over the base levels $\left(x_{1}^{*}\right)$ and the raw emission from rice expansion $\left(e_{2}\left(x_{2, v}^{*}-x_{1}^{*}\right)\right)$ overcomes the emissions savings $\left(\Delta e x_{1}^{*}\right)$ from growing lower emitting rice relative to the standard. This finding is consistent with that in Fischer [25] and Strand and Rosendahl [26].

In the case of negative emitting strategies the unintended consequence is that the incentive may be pretty ineffective. Under the assumption that we just want to get an increase in current sequestration or bioenergy activity $\left(x_{2}>x_{1}\right)$ where the technology is the same ( $\Delta c$ and $\Delta e$ are both zero), the emission difference in equation (16) reduces to zero. In such case, the carbon price fails to provide any incentive to increase current sequestration or bioenergy production activity.

Thus, for both positive and negative emitting strategies, the voluntary program can potentially give rise to unintended effects with it incurring the rebound effect or failing to provide an incentive to expand negative emission items.

2.3. Altering Payment Eligibility. Now we consider ways to alter the voluntary program to avoid the rebound effect for positive emitting strategies and encourage additional adoption of negative emitting strategies. As suggested by Strand and Rosendahl [26], production increase from positive emitting strategies should be restricted. To do this we add a new variable $x_{3}$ that equals the amount of voluntary enrollment beyond the BAU amount that is paid but is not offset by the baseline rate $e_{1}$ as follows:

$$
\begin{array}{ll}
\operatorname{Max} \pi & =p\left(x_{1}+x_{2}+x_{3}\right)-x_{1} C_{1}\left(x_{1}\right)-\left(x_{2}+x_{3}\right) C_{2}\left(x_{2}+x_{3}\right)-M\left[x_{2}\left(e_{2}-e_{1}\right)+x_{3} e_{2}\right] \\
& x_{2} \leq x_{1}^{*}, \quad \text { for } e_{2}>0, \\
\text { s.t. } & x_{1}+x_{2} \geq x_{1}^{*}, \quad \text { for } e_{2}<0, \\
& x_{1} x_{2}=0, \\
& x_{1}, x_{2}, x_{3} \geq 0 .
\end{array}
$$

Here, both $x_{2}$ and $x_{3}$ are net-emissions-reducing practices receiving carbon payments with $x_{2}$ being paid on net emission difference $\left(e_{2}-e_{1}\right)$ and $x_{3}$ receiving the full net emissions amount $\left(e_{2}\right)$. Economically $x_{3}$ will only enter the solution for negative cases (sequestration and bioenergy offsets) given higher or possibly equal costs for $x_{3}$ in comparison with $x_{1}$.

The first constraint for positive emitters limits the amount that is paid for $x_{2}$ to the BAU level of $x_{1}^{*}$, avoiding the rebound effect caused by $x_{2}$ being much greater than $x_{1}$. In practice this means only preprogram rice producing acreage could receive payments not any new acreage.

The second constraint for negative emitters requires that the production below the BAU level be either unpaid or paid by the net emission difference $\left(e_{2}-e_{1}\right)$. Then production expansion $x_{3}$ can be paid for full credit $\left(e_{2}\right)$ but this means additional new land or production must come in.
We solve the new objective function and get the solution for positive emitting strategies:

$$
\begin{aligned}
& x_{1, s}^{*}=x_{1}^{*}, \\
& x_{2, s}^{*}=0, \\
& x_{3, s}^{*}=0, \quad \text { when } M<\frac{c_{2}-c_{1}}{e_{1}-e_{2}}, \\
& x_{1, s}^{*}=0, \\
& x_{2, s}^{*}=x_{1}^{*}, \\
& x_{3, s}^{*}=0, \quad \text { when } M>\frac{c_{2}-c_{1}}{e_{1}-e_{2}} .
\end{aligned}
$$


$x_{2}$ no longer increases with the carbon price and remains constant at its upper bound of $x_{1}^{*}$. In this way, we are managed to restrict the total net emissions at

$$
\begin{gathered}
E_{v, s}^{*}=\frac{e_{2}\left(p-c_{1}\right)}{2 d}, \quad \text { when } M>\frac{c_{2}-c_{1}}{e_{1}-e_{2}}, \\
E_{v, s}^{*}-E B^{*}=\frac{\left(e_{2}-e_{1}\right)\left(p-c_{1}\right)}{2 d}<0, \quad \text { when } M>\frac{c_{2}-c_{1}}{e_{1}-e_{2}} .
\end{gathered}
$$

Comparing with the BAU net emissions, the voluntary program with the special payment design always yields lower total net emissions when the carbon price is above the critical value.

The solutions for negative emitting strategies are:

$$
\begin{aligned}
& x_{1, s}^{*}=x_{1}^{*}, \\
& x_{2, s}^{*}=0, \\
& x_{3, s}^{*}=0, \quad \text { when } M<A, \\
& x_{1, s}^{*}=0, \\
& x_{2, s}^{*}=x_{1}^{*}, \\
& x_{3, s}^{*}=\frac{c_{1}-c_{2}-M e_{2}}{2 d}, \quad \text { when } M>A,
\end{aligned}
$$

where $A$ is the critical value of carbon price above which netemissions-reducing alternatives will be adopted. We do not present the closed-form expression for $A$ due to its complexity but note that $A$ is smaller than the previously solved critical value $\left(\left(c_{2}-c_{1}\right) /\left(e_{1}-e_{2}\right)\right)$, because the payment for additional negative offsets is larger for alternative strategies. The total net emission level becomes

$$
\begin{aligned}
E_{v, s}^{*} & =\frac{e_{2}\left(p-c_{2}-M e_{2}\right)}{2 d}, \quad \text { when } M>A, \\
E_{v, s}^{*}-E_{v}^{*} & =-\frac{M e_{1} e_{2}}{2 d}<0, \quad \text { when } M>A .
\end{aligned}
$$

We can see the voluntary program with the special payment design always yields greater net emission reductions than that without alteration.

Through our theoretical analysis, we find the modified payment limits the production of positive emitting strategies at or below the baseline amount and incentivizes producers to expand their production of strategies with negative emissions precluding the unintended consequences.

\section{Empirical Study and Methods}

Now, we do an empirical based study using a sector model to see if any of these unintended cases occur in an ideal modeling world. Here, we simulate a voluntary carbon offset crediting program, and we test whether we could avoid unintended consequences by adding constraints above. We also compare results to a mandatory program under alternative program designs to gain insight on net emissions reduction effectiveness.

3.1. Simplified Overview of the Sector Model. For the study we use the agricultural component of the Forest and Agriculture Sector Optimization Model-Greenhouse Gas version (FASOMGHG) [29-31]. That model will be set up to simulate farmers' decisions under alternative forms of voluntary and mandatory carbon offset crediting programs.

Elaborating, the agricultural part of FASOMGHG $[9,29,31-33]$ is a dynamic, nonlinear, price endogenous programming model that maximizes the net present value of the sum of producer and consumers' surplus across the US agricultural sector over time by optimizing consumption, trade, land/water/labor allocation, processing, and production. Mathematically, the objective function is represented by the area under the product demand curves being less than the area under the factor supply curves as described in McCarl and Spreen [34].

Operationally, the model structure simulates multiperiod, multifactor, multicommodity market equilibria under perfect competition with the constraints of crop and livestock mix, resource limit for land, water, and labor, supply, and demand balances for primary and secondary commodities, trade balances for the US and the rest of world, and GHG balances. The model incorporates agricultural activities for over 100 commodity types across the conterminous US broken into 11 market regions and 28 foreign regions over up to 100 years on a 5 -year time step basis. FASOMGHG has already been widely employed to evaluate both economic and environmental impacts of a variety of mitigation strategies and policies. Our contribution to the model is that we incorporate the opt in features into the model and construct different baselines for voluntary market settings.

Equations (23) to (27) are a simplified representation of the model objective and constraints. We only include carbon payments structured for whether producers opt in or not in this brief mathematical exposition.

$$
\begin{aligned}
& \operatorname{Max} \int_{d} P_{d}(\mathrm{Q}) \mathrm{d} Q-\sum_{o}\left[c_{o}\left(X_{o}\right) * X_{o}\right] \\
& \quad-\sum_{o, g}\left(P_{c} * \mathrm{Pay}_{o} * \mathrm{GWP}_{g} * \mathrm{GHG}_{o, g}\right), \\
& \text { s.t. } Q-\sum_{o} f_{o}\left(X_{o}\right) \leq 0, \\
& \qquad \sum_{o} a_{o}\left(X_{o}\right) \leq b, \\
& e_{o, g}\left(X_{o}\right) * X_{o}-\mathrm{GHG}_{o, g}=0, \quad \text { for all } o, g, \\
& \quad Q, X_{o} \geq 0
\end{aligned}
$$

where

$g$ is a set of GHG accounts 
$o$ is an opt in set defining whether producers opt in or not to the program (base, yes_opt in)

$Q$ is a variable giving quantity of commodity consumption

$P_{d}(Q)$ is an inverse demand function giving price of commodities consumed

$X_{o}$ is a variable giving production activity level under opt in choice o

$c_{o}\left(X_{o}\right)$ is cost function varying with the choice of opting in

$P_{c}$ is the exogenous carbon price

$\mathrm{Pay}_{o}$ is a $0 / 1$ indicator for whether to pay carbon payments under opt in choice o

$\mathrm{GHG}_{o, g}$ is a variable giving net GHG emissions of type $g$ under opt in choice o

$f_{o}\left(X_{o}\right)$ is the yield of commodities produced by production under opt in choice o

$a_{o}\left(X_{o}\right)$ is the resource usage function of production activities under opt in choice $o$

$b$ is a vector of resource endowments

$e_{o, g}\left(X_{o}\right)$ is the amount of net emissions reduction relative to the standard of GHG $g$ when producing $X$ under opt in choice o

$\mathrm{GWP}_{g}$ is the global warming potential of GHG type $g$

Here, equation (23) is the objective function that is maximized where the maximand is the net present value of welfare including carbon payments and the costs of practices adopted including the cost of altering practices when opting in.

Equation (24) is the supply-demand balance constraint by time period for commodities and reflects production balanced with sales including any alterations in production when opting in.

Equation (25) is a resource endowment and reflects normal resource use under existing practices plus differences in resource use when opting in.

Equation (26) is the balance of total net GHG emissions including sequestration and biofuel offsets by opt in choice. The GHG accounting adds net effects across all the full production domain separately by whether producers opt in or not. The accounting can result in either positive or negative net effects. Various forms of this constraint will be used depending on the structure of the program.

More on the model is in Appendix A.

3.2. Scenarios to Run. In our empirical analysis, we setup a number of scenarios to look at different market setups. These span from no market to a mandatory to a couple of forms of a voluntary market. Details are as follows:

(i) Base (BAU) scenario-a base scenario is set up to simulate how farmers would behave in the absence of a carbon market. We set the carbon price equal to zero. The production level in the base scenario is denoted as $X^{b}$. (ii) Mandatory carbon program-the agricultural sector is treated as if it was capped with the carbon price applied to all changes in net emissions relative to a baseline level. We force all to participate and set the parameter Pay to 1. This scenario is set up for comparison purposes only as we assume the agricultural sector will not be capped.

(iii) Voluntary carbon program-here, producers can opt in. We set a nonzero carbon price $\left(P_{c}>0\right)$, for participants, those opting in $\left(\right.$ Pay $\left._{\text {yes_optin }}=1\right)$, and no payments for nonparticipants $\left(\right.$ Pay $\left._{\text {base }}=0\right)$ making only opting in producers eligible to receive carbon payments. Such a choice needs a baseline that encourages producers to voluntarily enroll and generate additional offsets. Two baseline specifications will be used.

- Per unit baseline: here we setup a per unit baseline level by practice corresponding to Section 2.2. We establish a standard calculated from the base scenario that opting in producers must do better than on a per unit of the practice undertaken basis. Details on practices and the GHG account setup are in Appendix B. Under this per unit baseline, opting in producers get paid upon the difference in emissions per unit for the activity they choose less than the standard baseline rate and enrolled activity levels.

- Per unit baseline plus participation constraints: here, we impose constraints and add variables equivalent to $\mathrm{x} 3$ above as developed in the theory section. In that case activity in excess of base scenario receives full payments when the net emission nature of the activity is negative (generally sequestration or bioenergy fossil fuel offsets) or pays full cost when the net emission nature of the activity is positive (for those that on net emit GHGs).

\section{Empirical Results}

Now, we report on the results by major category and scenario. We examine the net cost of the carbon payment program as well as the effect on net GHG emissions plus other market effects including changes in agricultural commodity production and prices, land usage and value, bioenergy production, and welfare. Additionality and leakage implications will also be addressed.

4.1. GHG Mitigation. Figure 1 presents annualized net GHG emissions by those opting in and not opting in under each alternative carbon market scenario under a $\mathrm{CO}_{2} \mathrm{e}$ price of $\$ 30 /$ ton. Net offsets, as an indication of the truly additional ones after accounting for leakage and the rebound effect, are calculated as the difference in net GHG emissions between the base scenario and those occurring under each alternative scenario.

In the results the net emission consequences are usually not equal to the gains paid to participants. This difference arises because of two factors. First, in most cases those not 


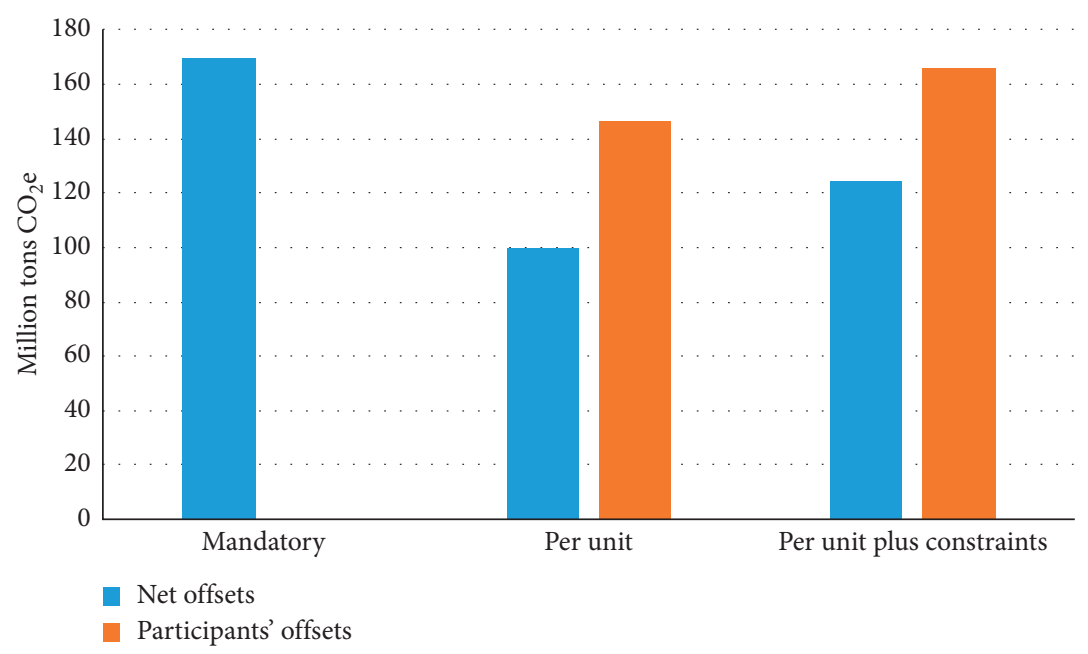

Figure 1: Annualized GHG offsets by scenario at $\$ 30 / \mathrm{tCO}_{2} \mathrm{e}$.

covered by the program choose to increase their net emissions or reduce sequestration relative to the baseline (a leakage effect) when responding to the market alterations caused by the actions of participants. Second, the per unit baseline may cause participants to expand qualifying "emission reductions" to levels beyond that in the base scenario (where $X_{o}>X^{b}$ for positive emitters as discussed above).

The mandatory participation scenario generates the most offsets as expected since it imposes the carbon price on all producers and does not pay for nonadditional production and penalizes for any within region leakage. This stimulates the greatest net emission reduction and penalizes for any and all emissions increase or sequestration/bioenergy offsets decrease while rewarding the opposite.

Once we bring in the payment and constraint design, we find that both net offsets and participants' offsets increase significantly. Also, we note this may be a second best solution as it is still less effective than the mandatory but likely hard to implement scenario.

Figure 2 shows more detailed GHG emission mitigation contributions by major strategy under the per unit and per unit plus constraints baselines across $\mathrm{CO}_{2}$ prices. Agricultural soil sequestration and bioenergy production are two primary categories of negative emission strategies. At low carbon prices, agricultural soil sequestration increases significantly compared to the base scenario and becomes the predominant strategy. That is because most of the agricultural soil sequestration practices are complementary with existing crop production and thus require relatively low costs as in [9]. When the carbon price gets higher, the share of agricultural soil sequestration declines due to the substantial increase in GHG offsets from bioelectricity production. Note that bioelectricity is not produced under the base scenario and at low carbon prices due to its high implementation costs but it has lifecycle GHG offset rates as high as $99 \%$. Such high offset rates combined with higher carbon prices induce producers to shift land and other resources out of traditional crop production to bioelectricity feedstock production. In addition, the per unit plus constraints scenario achieves more GHG offsets from bioenergy production than the per unit baseline because of additional incentives for bioenergy production.

4.2. Program Costs. We now turn to the average program cost per ton of mitigation. This is computed as annualized total carbon payments under the program divided by annualized tons of net $\mathrm{CO}_{2} \mathrm{e}$ offsets after considering both nonparticipants and participants net emissions. Although carbon credits are paid to participants only, we evaluate the effectiveness of carbon programs in mitigating GHG emissions considering possible leakage and nonadditionality. To accomplish this we use the total change in net $\mathrm{CO}_{2} \mathrm{e}$ offsets across all parties as the denominator instead of just participants' offsets. The average program cost for each program setup is listed in Table 1 .

The mandatory scenario has the lowest average program cost which also equals the $\mathrm{CO}_{2}$ e price. Any emission change relative to the base case is rewarded or penalized according to the $\mathrm{CO}_{2}$ e price so there is no leakage within the region associated with the mandatory program.

On the other hand, the average cost of voluntary carbon crediting programs is not equal to the $\mathrm{CO}_{2} \mathrm{e}$ price as nonparticipants' emissions are not restricted but are used in the calculation and leakage occurs. The per unit baseline also exhibits high average cost per effective ton $\mathrm{CO}_{2}$ e net emissions reduction cost. In addition to the nonparticipants leakage, the rebound effect is playing a part. As noted above, the per unit baseline is paid upon the difference in emissions per unit and as long as producers could reduce their emission rate, they are rewarded. The rebound effects occur and for some subcategories lead to a total emission increase and higher program costs. For example, we saw increased annualized corn production relative to the base case yielding $\mathrm{CO}_{2} \mathrm{e}$ net emissions increases under the per unit baseline but declined production under the per unit plus constraints baseline.

The per unit plus constraints case eliminates the rebound effects and provides more incentives toward expanding sequestration and bioenergy offsets. As previously shown, 


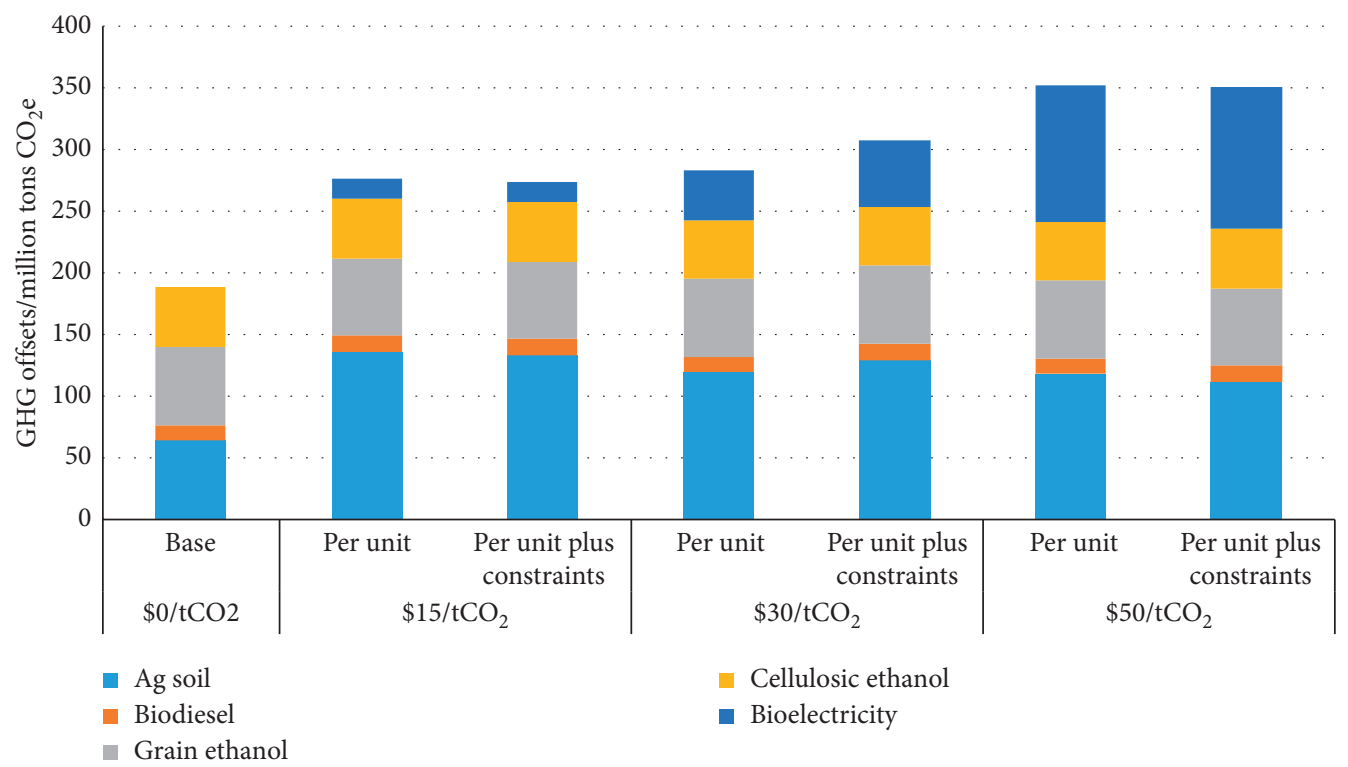

Figure 2: GHG mitigation strategies used under per unit and per unit plus constraints baselines across $\mathrm{CO}_{2}$ prices.

TABle 1: Total and average program costs at $\$ 30 / \mathrm{tCO}_{2} \mathrm{e}$.

\begin{tabular}{lccc}
\hline & Mandatory & Per unit & Per unit plus constraints \\
\hline Net offsets (in million tons $\mathrm{CO}_{2} \mathrm{e}$ ) & 169.39 & 99.85 & 124.33 \\
Participants' offsets (in million tons $\mathrm{CO}_{2} \mathrm{e}$ ) & - & 146.33 & 165.79 \\
Total program costs (in million \$) & $5,081.68$ & $6,266.10$ & $6,555.77$ \\
Average program costs (in \$/ton $\mathrm{CO}_{2} \mathrm{e}$ ) & 30.00 & 62.75 & 52.73 \\
\hline
\end{tabular}

the per unit plus constraints baseline induces $8 \%$ more GHG net offset from ag soil sequestration and bioenergy at a $\$ 30$ price. This results in achieving a lower average program cost than the per unit baseline. However, the existence of nonparticipants leakage still pushes up the average cost above the $\mathrm{CO}_{2}$ price.

4.3. Cropped Acres. Figure 3 illustrates the effects on annualized national crop acres in million acres under per unit and per unit plus constraints baselines for alternative $\mathrm{CO}_{2} \mathrm{e}$ prices. As that price increases, the percentage of opt in acres increases, indicating the obvious result that higher carbon prices lead to higher participation rates. However, as the carbon price increases from $\$ 30 / \mathrm{tCO}_{2} \mathrm{e}$ to $\$ 50 / \mathrm{tCO}_{2} \mathrm{e}$, the opt in acre percentage only increases slightly, showing that voluntary carbon programs are not able to encourage all producers to participate even at high carbon prices. In addition, agricultural soil sequestration practices are predominant mitigation strategies at low carbon prices. But as higher carbon prices, the agricultural soil sequestration no longer increases and bioenergy production begins to dominate as discussed in McCarl and Schneider [9]. In other words, energy crop production comes into play and competes for cropland. That is why we do not see use of less cropland even though we have less traditional crops produced. As shown in Figure 4, producers do not start producing more switchgrass based biopower at $\$ 15 / \mathrm{tCO}_{2} \mathrm{e}$. As the carbon price gets higher, biopower production grows significantly, almost all of which comes from opt in producers. At each carbon price, the per unit plus constraints case exhibits a higher level of switchgrass based biopower production than the per unit case.

4.4. Bioenergy Production. We mainly explore biodiesel and biopower production here because ethanol does not increase after 2020 due to the RFS assumptions in the model settings and the relatively lower $\mathrm{CO}_{2} \mathrm{e}$ offset rates. Figure 5 shows growth in the volume of biodiesel produced relative to production at the carbon price of $\$ 30 / \mathrm{tCO}_{2} \mathrm{e}$ by scenario.

We see the results that producers start to expand biodiesel production after 2025 because producers need time to react and construct biodiesel processing facilities. The per unit plus constraints baseline stimulates the largest amount of additional biodiesel production, indicating the per unit plus constraints setup provides effective incentives for biodiesel production. The mandatory scenario produces very large amounts of additional biodiesel in 2040 and 2045 and moderate amounts afterward. We also find that the per unit case has essentially the same level of biodiesel production as exhibited in the no carbon price because of the incentive lack as discussed in the theory section.

The change in feedstock usage for biodiesel production relative to the base scenario at alternative carbon prices under the per unit and per unit plus cases baselines 


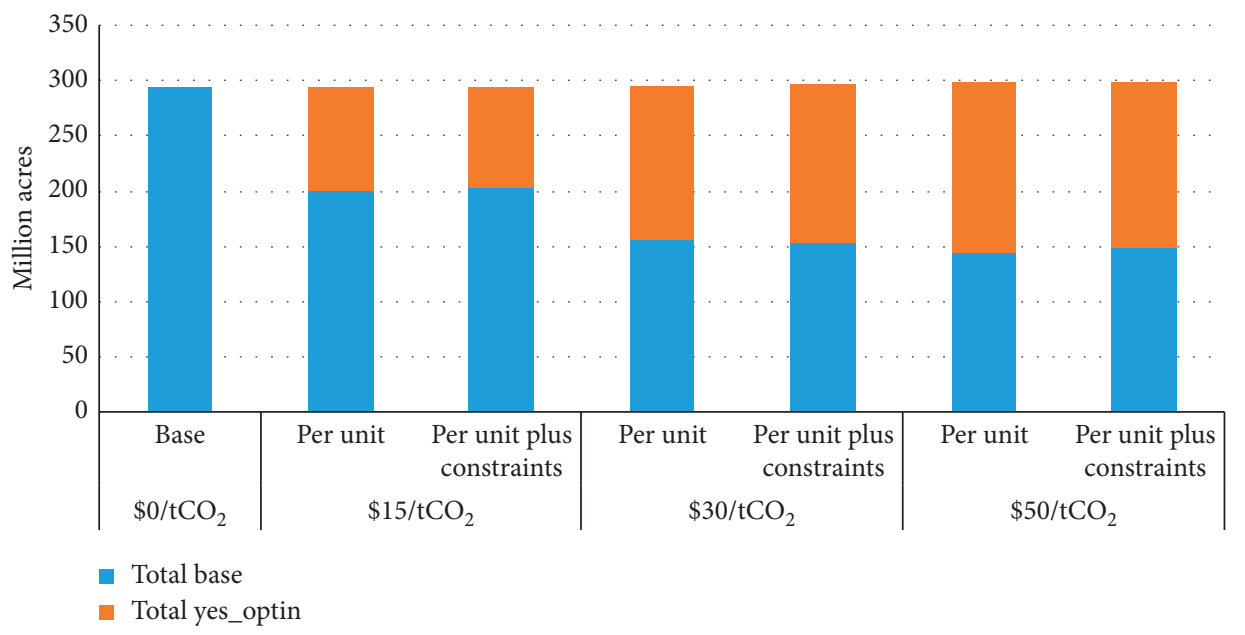

FigURE 3: Annualized national crop acres under per unit and per unit plus constraints scenarios across carbon prices.

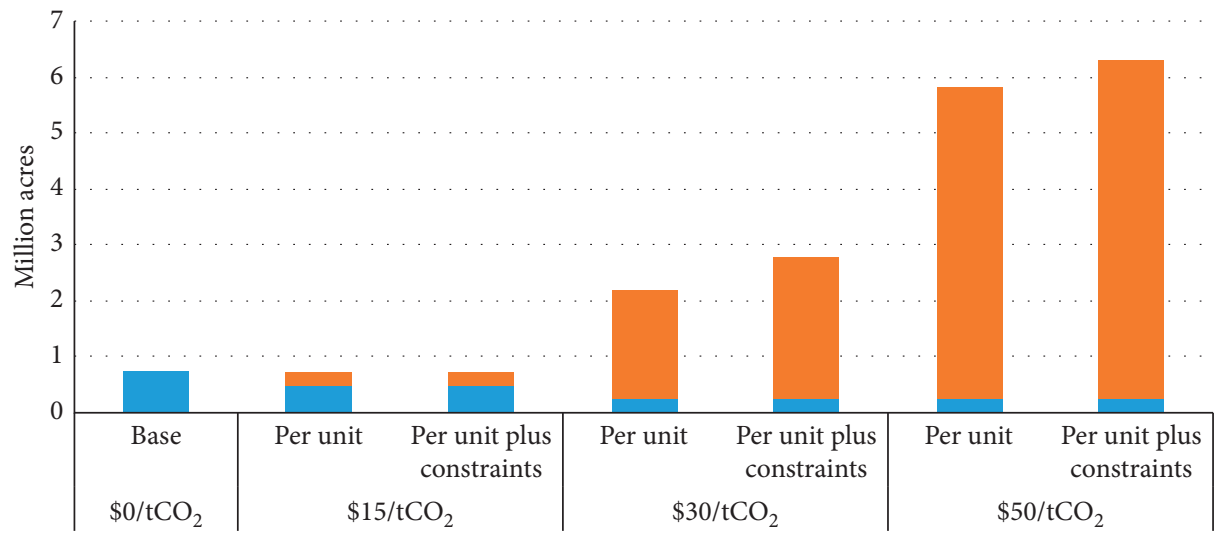

- Switchgrass base

- Switchgrass yes_optin

FigURE 4: Annualized national switchgrass acres under per unit and per unit plus constraints scenarios across carbon prices.

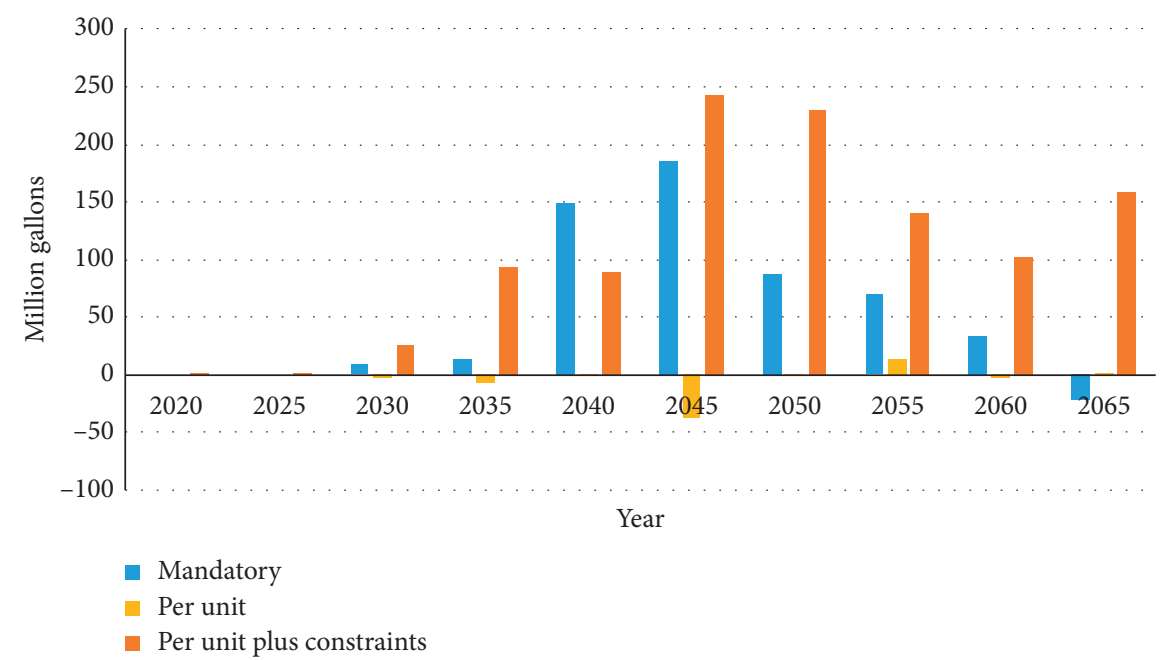

FIGURE 5: Biodiesel production additional to base at $\$ 30 / \mathrm{tCO}_{2} \mathrm{e}$. 


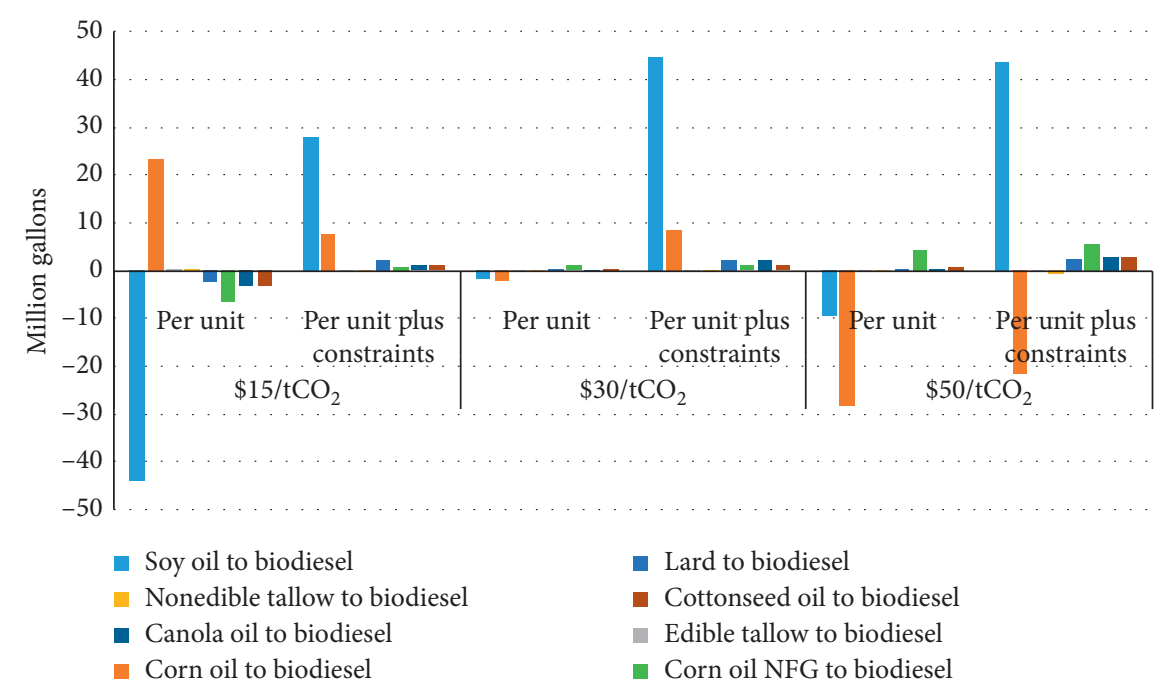

Figure 6: Additional biodiesel production composition from base across carbon prices.

is shown in Figure 6. At each carbon price, the per unit plus constraints baseline yields more production of biodiesel mainly from soybean oil. This result demonstrates that the per unit plus constraints case more effectively stimulates biodiesel production. In addition, we find biodiesel production increases with carbon prices at low prices. However, when the carbon price increases from $\$ 30 / \mathrm{tCO}_{2} \mathrm{e}$ to $\$ 50 / \mathrm{tCO}_{2} \mathrm{e}$, biodiesel production no longer expands mainly because of the less use of corn oil under both per unit and per unit plus constraints cases.

Figure 7 presents bioelectricity production over time under all alternative scenarios at $\$ 30 / \mathrm{tCO}_{2} \mathrm{e}$. The mandatory scenario consistently achieves a high level of bioelectricity production. The per unit plus constraints baseline exhibits high levels peaking its bioelectricity production from 2035 to 2055 but then later having it fall.

We now look deeper into the breakdown of feedstock use for bioelectricity. For simplicity, we have combined processes with and without cofiring for each biofeedstock used. Bioelectricity production expands significantly with increased carbon prices. At the carbon price of $\$ 15 / \mathrm{tCO}_{2} \mathrm{e}$, bioelectricity is primarily processed from manure (Table 2). As the carbon price increases to $\$ 30 / \mathrm{tCO}_{2} \mathrm{e}$, we observe increasing use of switchgrass and crop residues especially wheat residues. When the carbon price is $\$ 50 / \mathrm{tCO} 2 \mathrm{e}$, switchgrass expands and is the predominant biofeedstock. We also see the use of corn residues increases substantially and willow comes into play. Note that biodiesel production stops expanding with less use of corn oil at high carbon prices. We observe a trend of shifting resources from biodiesel to bioelectricity due to the higher GHG reduction of bioelectricity.

4.5. Market Effects. Table 3 presents annualized national index numbers for commodity prices and quantities under all market design scenarios at $\$ 30 / \mathrm{tCO}_{2} \mathrm{e}$. The results show that the introduction of voluntary carbon crediting programs leads to less conventional farm production and higher commodity prices with higher land values. This is because agricultural producers shift land use from agricultural production to bioenergy production to receive more carbon payments as in Schneider and McCarl [35]. In turn production falls and commodity prices generally increase with cropland becoming more valuable [8].

We illustrate the national index number changes across carbon prices under the per unit plus constraints scenario in Figure 8 . When the carbon price is low, impacts on price and trade indexes are quite minimal. When the carbon price is high, we do see higher commodity prices, fewer exports, and more imports due to less agricultural product supply.

Welfare is also a concern. Table 4 displays percentage changes from the base producers' and consumers' surplus for all the program setup scenarios. Note that the surplus discussed here does not cover: (1) the social cost and benefits of altered GHG emission reductions, erosion, or other environmentally related changes and (2) the government costs of raising the money for program payments and administration. The most noticeable change is the gain in domestic producers' surplus. Despite less agricultural production, the domestic producers' surplus increases under all scenarios since carbon payments provide an additional source of income for program participants and prices are somewhat higher. The mandatory scenario generates the largest increase in the domestic producers' surplus which is directly related to the largest amount of carbon net emissions reductions and resulting payment applied to all producers in the agricultural sector. The per unit plus constraints scenario generates a higher domestic producers' surplus than the per unit scenario does since it pays more for higher sequestration and bioenergy production in spite of actually having a lower average payment for net emission offsets. Changes in domestic and overseas consumers' surpluses are negligible because the commodity price impact is quite small. Overseas producers gain as a result of fewer US exports. Overall, we achieve a net gain in world welfare under all scenarios. 


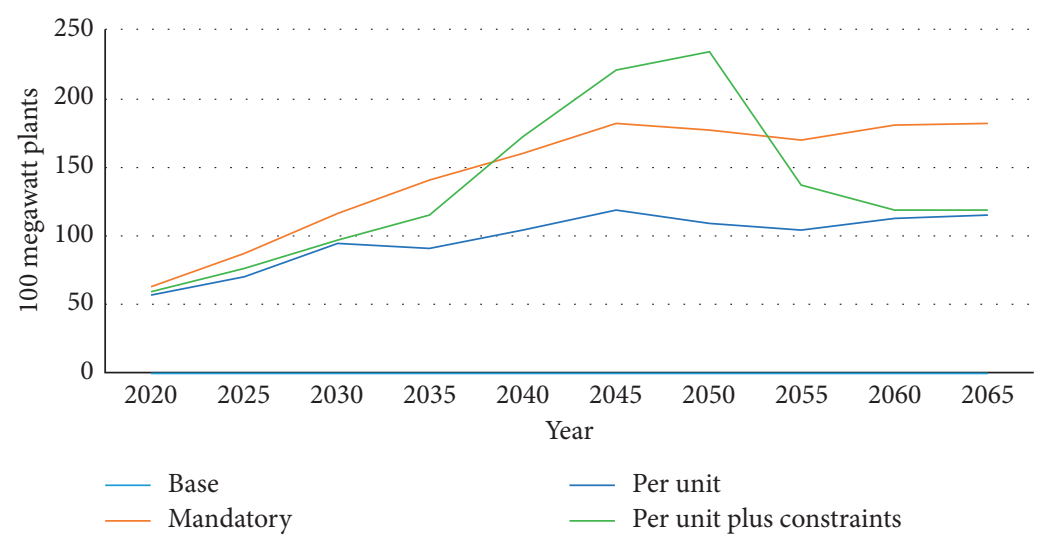

Figure 7: Bioelectricity production over time at $\$ 30 / \mathrm{tCO}_{2} \mathrm{e}$.

TABLE 2: Annualized electricity production breakdown in number of 100 megawatt plants.

\begin{tabular}{|c|c|c|c|c|c|c|}
\hline \multirow{2}{*}{ Biofeedstock used } & \multicolumn{2}{|r|}{$\$ 15 / \mathrm{tCO}_{2}$} & \multicolumn{2}{|r|}{$\$ 30 / \mathrm{tCO}_{2}$} & \multicolumn{2}{|r|}{$\$ 50 / \mathrm{tCO}_{2}$} \\
\hline & Per unit & Per unit plus constraints & Per unit & Per unit plus constraints & Per unit & Per unit plus constraints \\
\hline Corn residue & & & 0.31 & 4.84 & 48.19 & 52.85 \\
\hline Sorghum residue & & & 2.45 & 4.76 & 12.77 & 6.85 \\
\hline Wheat residue & 0.01 & 0.02 & 9.02 & 14.80 & 17.16 & 18.07 \\
\hline Barley residue & 0.35 & 0.41 & 5.15 & 5.87 & 6.46 & 6.57 \\
\hline Oats residue & & & 0.32 & 0.48 & 0.45 & 0.49 \\
\hline Bagasse & & & 0.01 & 0.02 & 0.82 & 0.67 \\
\hline Switchgrass & 0.11 & 0.12 & 24.90 & 34.41 & 76.19 & 81.30 \\
\hline Willow & & & & & 0.10 & 0.36 \\
\hline Lignin & & & 6.44 & 6.70 & 5.40 & 5.24 \\
\hline Manure & 16.73 & 16.25 & 16.37 & 16.18 & 17.13 & 16.54 \\
\hline Beef manure & 0.59 & 3.01 & 0.67 & 3.18 & 2.62 & 2.91 \\
\hline Dairy manure & 7.30 & 5.36 & 7.58 & 5.26 & 4.88 & 5.17 \\
\hline
\end{tabular}

TABLE 3: Annualized national index numbers at $\$ 30 / \mathrm{tCO}_{2} \mathrm{e}$.

\begin{tabular}{lccccc}
\hline Agtype & Item & Base & Mandatory & Per unit & Per unit plus constraints \\
\hline AllFarmProd & Production & 100.00 & 99.77 & 96.37 & 96.34 \\
AllFarmProd & Price & 100.00 & 99.36 & 100.32 & 100.05 \\
AllFarmProd & Exports & 100.00 & 99.63 & 100.16 & 99.53 \\
AllFarmProd & Imports & 100.00 & 99.86 & 100.06 & 100.05 \\
Cropland & Price & 100.00 & 99.37 & 103.89 & 104.54 \\
\hline
\end{tabular}

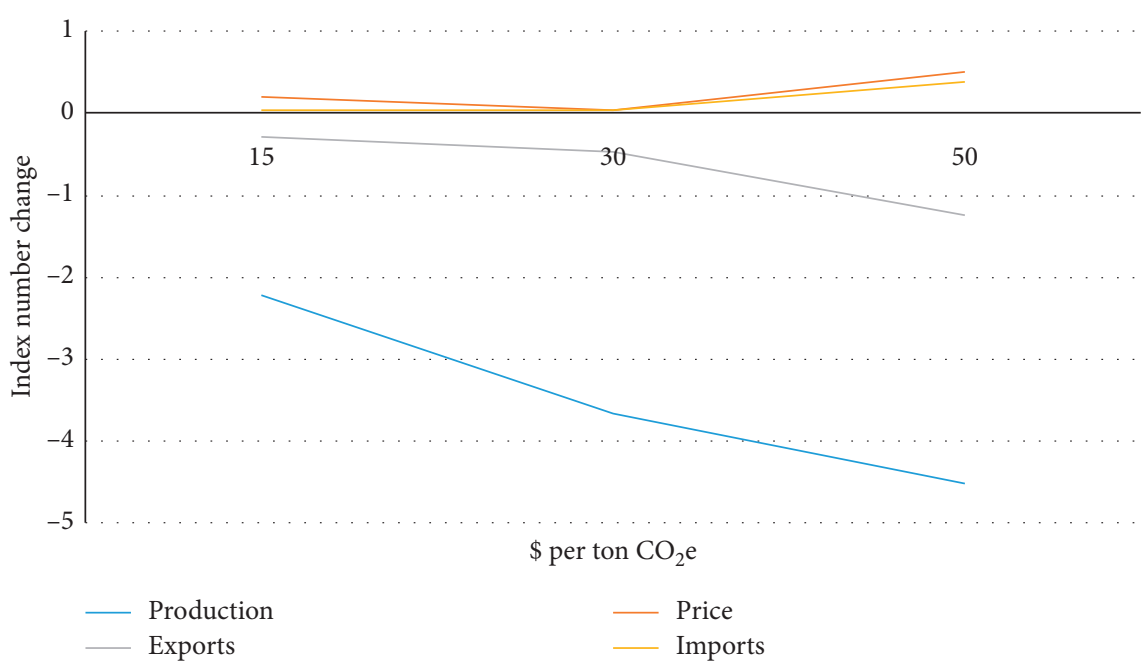

Figure 8: Annualized national index number changes under per unit plus constraints scenario across carbon prices. 
Table 4: Percentage change from base in welfare at $\$ 30 / \mathrm{tCO}_{2} \mathrm{e}$.

\begin{tabular}{lccc}
\hline & Mandatory (\%) & Per unit (\%) & Per unit plus constraints (\%) \\
\hline Domestic consumers' surplus & -0.05 & 0.00 & -0.01 \\
Domestic producers' surplus & 3.50 & 2.01 & 2.63 \\
Overseas consumers' surplus & -0.01 & 0.00 & -0.01 \\
Overseas producers' surplus & 0.29 & -0.05 & 0.40 \\
Total & 0.04 & 0.04 & 0.04 \\
\hline
\end{tabular}

\section{Conclusion and Policy Implications}

As an often noncapped sector in GHG trading markets, agriculture can provide offsets by reducing GHG emissions, enhancing sequestration, or producing feedstocks for bioenergy that replaces higher emitting fossil based energy forms but needs incentives to do so. Voluntary carbon markets can provide such incentives and allow producers to join at their discretion. We set up a baseline condition where participants have to do better at reducing emissions relative to a per unit standard or produce more sequestration or bioenergy feedstocks again relative to a standard. Herein, we analyze market designs under such a situation.

In terms of market design, we first examine the case where a producer is paid the difference between emissions under an improved practice and the emissions under currently used practice (i.e., if current rice cultivation generates $x$ tons of emissions per hectare and an improved practice yields $y$ we will pay for the $x-y$ savings times the land area enrolled). In that case, we find there is an incentive to expand the participating land area beyond preexisting area, thus generating a rebound effect. We subsequently suggest imposition of a maximum participating land area constraint set at the preexisting area which could likely be established using remote sensing.

Subsequently we turned to the sequestration/bioenergy offset case finding that payments relative to a standard discouraged participation. There we suggest only paying relative to the standard on the preexisting area then dropping the standard to zero paying for the full amount for additional participation. Therefore, adding proper constraints to per unit baseline could effectively reduce unintended effects. We also find as carbon prices increase, strategies switch from low-cost such as agricultural soil sequestration to higher-cost but greater per unit land emission offset strategies such as bioenergy production. This is consistent with Forest Trends' Ecosystem Marketplace [36] observation that in 2019 over-the-counter transaction voluntary offset volumes for renewable energy surged by 78 percent while agriculture, forestry, and other land use (AFOLU) volumes dropped by 28 percent.

Our empirical work basically shows imposing such constraints eliminates the rebound effect for emitters and the participation disincentives for those selling sequestration or bioenergy offsets. From a policy standpoint we believe imposing the constraints can help generate cheap, additional actions and feel that imposing the constraints can be done via a requirement that participants prove the amount of preexisting use of the emitting, sequestering, and bioenergy feedstock activities much as done in the US farm and insurance programs. This allows effective ways to harness sectoral potential to reduce emissions relative to current conditions and increase sequestration and bioenergy feedstock production well beyond current levels.

Although our analysis focuses on agricultural sector, the policy design may also be applicable to other voluntary market settings for sectors such as forestry and wetland management. For example, expansions in reforestation may yield substantial carbon benefits but proper incentives or subsidies need to be provided to cause the expansion and reach the optimal harvest cycle with a reward to all of the extra carbon not a measure relative to gains under small implementations of such practices. Such incentives would also likely gain cobenefits in the form of environmental services [37]. Note however caution would be needed to not get carried away with the cobenefits when they make an alternative look better but if one looks at all alternatives there may be other cases where cobenefits are even greater [38]. As for wetland restoration, four project-specific carbon offsets methodologies are approved but no transactions have been made yet because of high cost and lack of proper incentives [39]. We believe that with our baseline design their attractiveness would increase.

There are several limitations to our current study. Since FASOMGHG is used in the empirical phase of our study, our results and discussion depend heavily on its embodied assumptions, data, and model structure including projections of future crop and livestock yields along with ethanol mandates. Also, the uncertainty and permanence issues involved with mitigation are not fully considered in this analysis. Incorporating an uncertainty or permanence discount may alter our results.

\section{Appendix}

\section{A. Additional Details on FASOM}

The major categories of GHG mitigation strategies included in FASOMGHG are listed in Table 5, as well as the types of GHGs affected by each strategy. Emissions can be reduced through altering tillage, crop management, manure and livestock management, and land use. Tillage and land use change lead to sequestration as do some crop-related actions. Carbon saturation of soils is modeled for the sequestration alternatives (see discussion in $[29,30,40,41]$ for notes on the model implementation approach). GHG emissions from energy use can be reduced by using biomass to replace fossil fuels in electricity generation, replace gasoline with biomass produced ethanol and production, or replace diesel with biodiesel. Bioenergy production can possibly play a major role in mitigating GHG emissions as energy use GHG emissions [31] are large (with an 
TABLE 5: GHG mitigation strategies in agricultural part of FASOMGHG.

\begin{tabular}{lccc}
\hline Source/sink & Mitigation strategy & \multicolumn{2}{c}{$\mathrm{GHG}$ affected } \\
& & $\mathrm{CO}_{2}$ & $\mathrm{CH}_{4}$ \\
\hline Manure management & Emission & $\mathrm{X}$ \\
Crop mix alteration & Emission, sequestration & $\mathrm{X}$ \\
Crop fertilization alteration & Emission, sequestration & $\mathrm{X}$ \\
Crop input alteration & Emission & $\mathrm{X}$ \\
Crop tillage alteration & Emission, sequestration & $\mathrm{X}$ & $\mathrm{X}$ \\
Grassland conversion & Sequestration & $\mathrm{X}$ & $\mathrm{X}$ \\
Irrigated/dry land conversion & Emission & $\mathrm{X}$ & $\mathrm{X}$ \\
Rice acreage & Emission & $\mathrm{X}$ & $\mathrm{X}$ \\
Enteric fermentation & Emission & $\mathrm{X}$ \\
Livestock system change & Emission & $\mathrm{X}$ \\
Livestock herd size & Emission & $\mathrm{X}$ \\
Bioenergy & & $\mathrm{X}$ \\
Conventional ethanol & & $\mathrm{X}$ \\
Cellulosic ethanol & & $\mathrm{X}$ \\
Biodiesel & Fossil fuel substitution & $\mathrm{X}$ \\
Bioelectricity & Fossil fuel substitution & $\mathrm{X}$ \\
\hline
\end{tabular}

*Source: [29].

over $80 \%$ share in the US). Moreover, bioenergy production does not have issues of saturation or reversibility like soil sequestration [31]. In addition, there exists interdependence between different mitigation strategies. The modeling framework considers all GHG mitigation alternatives simultaneously to capture tradeoffs and resource competition. For example, if cropland is converted to switchgrass, it is no longer available to convert to grasslands or to have crop residues harvested [5].

Bioenergy types covered in FASOMGHG include crop ethanol, cellulosic ethanol, biodiesel, and bioelectricity. Each form of bioenergy can be processed using a variety of selected agricultural and forestry commodities within the model [31]. In brief, the possibilities and means of production are as follows:

(i) Biodiesel production can be achieved through conversion of canola oil, corn oil, lard, poultry fat, soybean oil, tallow, or yellow grease into biodiesel, which replaces petroleum-based diesel fuel.

(ii) Bioelectricity production can be achieved through usage of bagasse, crop residues, energy sorghum, per unit plus constraints poplar, lignin, manure, miscanthus, sweet sorghum pulp, switchgrass, willow, wood chips, logging residues, or milling residues as inputs to electric generating power plants in place of coal (through either cofiring or dedicated biomass plants).

(iii) Cellulosic ethanol production can be achieved through usage of bagasse, crop residues, energy sorghum, per unit plus constraints poplar, miscanthus, sweet sorghum pulp, switchgrass, willow, wood chips, logging residues, or milling residues as feedstocks to produce cellulosic ethanol, which replaces gasoline.

(iv) Starch or sugar-based ethanol production can be achieved through usage of barley, corn, oats, rice, sorghum, sugar, sweet sorghum, or wheat in a process that converts these commodities to ethanol that in turn is a replacement for gasoline.

The GHG reduction provided by bioenergy production is equal to the GHGs emitted from burning and producing the fossil fuel replaced less the GHG emissions of producing, transporting, and processing the bioenergy feedstocks. Listed in Table 6 is a lifecycle accounting of emission reduction rates of various bioenergy production possibilities drawn from McCarl [8]. The accounting shows that the target bioenergy type and utilized biofeedstock greatly influence emission reduction rates. Overall bioelectricity with cofiring has the highest GHG emission reduction while crop ethanol replacement of gasoline yields the lowest. Biodiesel processed with soybean oil has a much higher offset rate than that processed with corn oil. We will see how the focus of bioenergy production changes as we increase our carbon prices and switch opt in baselines.

FASOMGHG also incorporates several features regarding bioenergy production to better mimic the real situation. Biofuel mandates such as RFS2 are introduced along with the costs of crossing the blend wall and collectively these limit the attractiveness of ethanol production. Asset fixity is specified in the model [42] requiring that refining and electrical generating facilities once built are immobile and typically can handle only one class of feedstock. FASOMGHG assumes all bioenergy plants to have a lifespan of 30 years. The application of asset fixity prevents sudden regional and feedstock discontinuity in bioenergy production but also sets capacity limits for newly introduced or high-cost bioenergy like bioelectricity due to substantial upfront capital investment costs [42].

\section{B. Additional Details on Model Scenario Setups}

B.1. Base Scenario. The base scenario is set up with no carbon market pricing. It simulates how farmers would behave in the absence of a carbon market. We get the base solution by eliminating the choice allowing nonparticipation only and 
TABle 6: Percentage offset in carbon dioxide equivalent emissions from the usage of a biofeedstock.

\begin{tabular}{|c|c|c|c|c|c|c|c|c|}
\hline \multirow{2}{*}{ Commodity } & \multicolumn{3}{|c|}{ Liquid fuels } & \multicolumn{4}{|c|}{ Cofired electricity } & \multirow{2}{*}{$\begin{array}{l}\text { Electricity } \\
\text { Fire } 100 \%\end{array}$} \\
\hline & Crop ethanol & Cellulosic ethanol & Biodiesel & $5 \%$ & $10 \%$ & $15 \%$ & $20 \%$ & \\
\hline Corn & 17.2 & & & & & & & \\
\hline Hard red winter wheat & 16.1 & & & & & & & \\
\hline Sorghum & 27.8 & & & & & & & \\
\hline Sugarcane & 64.9 & & & & & & & \\
\hline Soybean oil & & & 95.0 & & & & & \\
\hline Corn oil & & & 39.1 & & & & & \\
\hline Switchgrass & & 56.7 & & 86.3 & 86.5 & 86.2 & 86.0 & 75.1 \\
\hline Poplar & & 52.6 & & 84.1 & 84.4 & 84.1 & 83.8 & 71.3 \\
\hline Willow & & 62.8 & & 90.9 & 91.0 & 90.8 & 90.7 & 83.4 \\
\hline Softwood log residue & & 79.3 & & 99.2 & 99.1 & 99.1 & 99.0 & 97.3 \\
\hline Hardwood log residue & & 79.4 & & 99.0 & 98.9 & 98.8 & 98.8 & 96.3 \\
\hline Corn cropping residue & & 69.8 & & 89.2 & 89.4 & 89.2 & 89.0 & 80.1 \\
\hline Wheat cropping residue & & 56.4 & & 93.3 & 93.4 & 93.2 & 93.1 & 87.2 \\
\hline Manure & & & & 99.5 & 99.4 & 99.2 & 99.1 & 96.4 \\
\hline Bagasse & & 95.7 & & 98.1 & 98.1 & 98.1 & 98.0 & 96.5 \\
\hline Lignin & & & & 91.3 & 91.5 & 91.3 & 91.2 & 85.8 \\
\hline Lignin hardwood & & & & 91.4 & 91.5 & 91.4 & 91.2 & 85.7 \\
\hline Lignin softwood & & & & 96.2 & 96.3 & 96.2 & 96.2 & 94.1 \\
\hline
\end{tabular}

*Source: [8].

setting the carbon price equal to zero. Consequently the whole carbon payment part has no effect. We denote the baseline net GHG emissions as $\mathrm{GHG}_{g}^{b}$ and production activity level as $X^{b}$.

B.2. Mandatory Carbon Program. Under the mandatory carbon program scenario, the agricultural sector is treated as if it was capped with the carbon price applied to all changes in net emissions relative to a baseline level with emission reductions rewarded and increases penalized. We drop the opt in choice (o) of not participating only model mandatory participation and set the parameter Pay to 1 .

B.3. Voluntary Carbon Programs. A voluntary carbon crediting program is modeled where producers can opt in to contribute to net emission reductions. Such a choice needs a baseline that encourages producers to voluntarily enroll generating offsets at low costs. Producers who opt in would get paid for their reductions in net emissions for the greenhouse gas account relative to a baseline amount. They would also be liable for any increase in net emissions in any account. Producers who do not opt in have no direct financial implications arising from changes in their net emissions. In this case, issues of additionality can occur if producers enroll to do things they would have done anyhow and issues of leakage when nonparticipants and people in other regions respond to market signals and increase net emissions. In addition, the baseline needs to be defined to be applicable only to those opt in as payments need to be made are dependent only when certain producers choose whether or not to opt in a particular activity.

Two baseline specifications will be used as follows:

(i) Per unit baseline:

Here, we setup a baseline level by practice establishing a standard that opting in producers must do better than on per unit of the practice undertaken basis. To do this we construct a per unit baseline where, for example, for crop production the net emissions will be judged relative to a standard level as observed in the baseline. Specifically, we define a set by of GHG types with a per unit baseline as follows:

Baseline_agtill: baseline net emissions from ag tillage

Baseline_crop: baseline net emissions from crop production

Baseline_bioenergy: baseline net emissions from bioenergy

Baseline_enteric: baseline net emissions from enteric fermentation

Baseline_manure: baseline net emissions from manure

Baseline_bioenergypen: baseline net emissions from bioenergy penetration

Baseline_idlepasture: baseline net emissions from idle pasture

Baseline_pasturelandusechange: baseline net emissions from pasture land use

Baseline_grazinguse: baseline net emissions from grazing land use

To calculate the baseline, we need a per unit net emissions estimate applicable to each of the accounts above that would arise in the absence of a carbon market. To get this, we solve the model without any carbon payments and compute the related GHG net emissions per unit for each of the above activity types in each region. To do this, we compute total emissions and divide by the activity level (acres under each tillage practice, acres of a crop, head of an animal type, or tons of biomass feedstock used, etc.). The total GHG emissions are computed on a $\mathrm{CO}_{2}$ equivalent basis by activity category above (bg) and 
then divided by the number of units produced under that activity to get a baseline level of per unit net GHG emissions. The formula for this is

$$
b r_{b g}=\frac{\sum_{g \in b g} \mathrm{GWP}_{g} * \mathrm{GHG}_{g}^{b}}{X_{b g}^{b}} .
$$

For example, suppose we wish to calculate the baseline emission rate on a per acre basis for a particular crop; to do this, we add the per acre emissions generated in the baseline, zero carbon price, and no opt in runs across all the GHG emission categories that fall into the crop emissions component of the bg set across all acres of that crop grown in a region and then divide by total acres of that crop in that region. This would involve adding carbon dioxide emissions from direct use of fossil fuel, grain drying, fertilizer usage, pesticide usage, and water pumping, and then adding in the nitrous oxide GWP times the amount of nitrous oxide emissions from crop residue retention, fertilizer usage, agricultural burning plus the methane GWP times the methane emissions from agricultural residue burning, and, if on rice, rice cultivation. We do not include tillage effects under crop production as that is treated in another account but the model requires opted in tillage when treating opted in crop production.

To avoid double counting, the bioenergy baseline calculation only involves offsets and emissions emerged from biofeedstocks processing and transportation but not the production of those biofeedstocks. However we do require that opted in bioenergy activities must use biofeedstocks produced from opted in crops that in turn use opted in tillage. Adding this requirement on the bioenergy makes sure we take into account the full lifecycle including associated crop production, fertilization, and tillage emissions.

The resultant net emissions per unit can be either positive or negative depending on the nature of the particular activity and the contained GHG accounts. A positive emission rate indicates the standard an opted in activity must achieve is one that exhibits a net reduction in emissions relative to baseline levels. Similarly, a negative standard means that the sequestration or bioenergy offset under the opted in activity must exhibit a larger level of offset than the level realized per acre or unit of energy than the one realized under baseline activity.

Under this per unit baseline, opting in producers get paid upon the difference in emissions per unit for the activity they choose less than the standard baseline amount per acre, head, or unit of bioenergy. In turn this will be multiplied by enrolled activity levels. This means they get paid if they either reduce emissions or increase sequestration/bioenergy offsets relative to the baseline practice. Nonparticipants are not paid or penalized. Thus, the objective function and constraints of GHG accounts are modified to become

$$
\begin{aligned}
& \max \int P_{d}(Q) \mathrm{d} Q-\sum_{o}\left(c_{o}\left(X_{o}\right) * X_{o}\right)-P_{c} \\
& *\left(\sum_{g} \mathrm{GWP}_{g} * \mathrm{GHG}_{\text {yes_optin }, g}-\sum_{b g} b r_{b g} * X_{\text {yes_optin }}\right) \\
& \text { s.t. } \quad e_{o, g}\left(X_{o}\right) * X_{o}=\mathrm{GHG}_{o, g}, \quad \text { for all } o, g .
\end{aligned}
$$

The net result is that the objective function contains only the difference in GHG emissions per unit achieved by participants.

(ii) Per unit plus constraint case:

Here, we do the per unit case plus adding the constraints developed in the theory section above.

First, we place any restriction on increases in $X$ beyond baseline levels for each account

Second, we restrict the amount not paid plus that paid on improvement relative to the baseline to be greater than or equal to the baseline amount Third, we add a second opt in option that operates relative to a zero standard

The model is set up as follows:

$$
\begin{aligned}
& \max \int P_{d}(Q) \mathrm{dQ}-c_{\text {base }}\left(X_{\text {base }}\right) * X_{\text {base }}-c_{\text {yes_optin }}\left(X_{\text {yes_optin }}+Y_{\text {yes_optin }}\right) *\left(X_{\text {yes_optin }}+Y_{\text {yes_optin }}\right) \\
& \quad-P_{c} *\left(\sum_{g} \mathrm{GWP}_{g} * \mathrm{GHG}_{\text {yes_optin, } g}-\sum_{b g} b r_{b g} * X_{\text {yes_optin }}\right), \\
& \text { s.t. } Q-f_{\text {base }}\left(X_{\text {base }}\right)-f_{\text {yes_optin }}\left(X_{\text {yes_optin }}+Y_{\text {yes_optin }}\right) \leq 0, \\
& a_{\text {base }}\left(X_{\text {base }}\right)+a_{\text {yes_optin }}\left(X_{\text {yes_optin }}+Y_{\text {yes_optin }}\right) \leq b, \\
& e_{\text {yes_optin }}\left(X_{\text {yes_optin }}+Y_{\text {yes_optin }}\right)=\mathrm{GHG}_{\text {yes_optin, } g}, \quad \text { for all } g
\end{aligned}
$$




$$
\begin{aligned}
& e_{\text {base }, g}\left(X_{\text {base }}\right) * X_{\text {base }}=\mathrm{GHG}_{\text {base }, g}, \quad \text { for all } g \\
& X_{\text {base }}+X_{\text {yes_optin }} \geq X^{b}, \quad \text { for net emission reduction activities, } \\
& X_{\text {yes_optin }} \leq X^{b}, \quad \text { for net emitting activities. }
\end{aligned}
$$

The variable $Y_{\text {yes_optin }}$ appears in all equations and is the one depicting opt in operation against a zero baseline while $X_{\text {yes_optin }}$ is the one depicting operation against the nonzero standard baseline. It represents activity in excess of baseline levels and is constrained for positive net emissions but not for negative cases.

More specifically for cases where the baseline is generating negative net emissions (sequestration or offsets) equation (B.8) requires the amount of activity not receiving payments $\left(X_{\text {base }}\right)$ plus those eligible to receive payments but at a level offset by the per unit standard $\left(X_{\text {yes_optin }}\right)$ must be greater than or equal to the level of production baseline. That deals with the nonadditional production (i.e., that which would have existed in the absence of a program). In that case activity in excess of baseline levels falls into the variable $Y$ and receives full payments when the net emission nature of the activity is negative (generally sequestration or bioenergy fossil fuel offsets) or pays full cost when the net emission nature of the activity is positive (for those that on net emit GHGs).

On the negative emission side constraint (B.8) makes sure baseline negative net emissions producers get payments only if they improve relative to what was being done in the baseline (the standard) while new entrants receive full payments from a base of zero. Such a payment design encourages additional producers to expand their sequestration and bioenergy production to receive full credits from the production above baseline.

For entities with positive baseline emissions equation (B.9) limits the activity paid to that occurring in the baseline, without carbon payment case. Beyond that the per unit baseline is zero and payments only arise if the activity can be turned from a net emitter to a net sequestration or a bioenergy offsetter.

The two constraints together deal with both nonadditional and additional cases and prevent the rebound effect from positive emitters while encouraging new negative emitters to expand production.

\section{Data Availability}

The data used to support the findings of this study are available from the corresponding author upon request.

\section{Additional Points}

Highlights. (i) As a noncapped sector, agriculture can voluntarily participate into carbon markets by providing emission offsets, enhancing sequestration, or providing feedstocks for low emitting bioenergy but to do this there is a need for incentives. (ii) Unintended emission effects could be avoided by providing a preprogram baseline on the replacement of high emitting activities with lower ones. (iii) Unintended disincentives for sequestration and bioenergy feedstock production could be reduced by paying the full amount for activity above current levels and only paying for improvements on existing production. (iv) The simulation shows these provisions preclude rebound effects and incentivize greater levels of sequestration/bioenergy with bioenergy production becoming dominant at high carbon prices.

\section{Conflicts of Interest}

The authors declare that they have no conflicts of interest.

\section{Acknowledgments}

This research was funded by the Fundamental Research Funds for the Central Universities (Grant no. JBK2101049).

\section{References}

[1] R. N. Stavins, "Experience with market-based environmental policy instruments," in Handbook of Environmental Economics, Environmental Degradation and Institutional Responses, pp. 355-435, Elsevier, Amsterdam, Netherlands, 2003.

[2] R. G. Newell, W. A. Pizer, and D. Raimi, "Carbon markets 15 Years after Kyoto: lessons learned, new challenges," Journal of Economic Perspectives, vol. 27, no. 1, pp. 123-146, 2013.

[3] P. R. Shukla, J. Skea, E. Calvo Buendia et al., IPCC, 2019: Climate Change and Land: An IPCC Special Report on Climate Change, Desertification, Land Degradation, Sustainable Land Management, Food Security, and Greenhouse Gas Fluxes in Terrestrial Ecosystems, Cambridge University Press, Cambridge, UK, 2019.

[4] B. C. Murray, "Why have carbon markets not delivered agricultural emission reductions in the United States," Choices, vol. 30, no. 2, pp. 1-5, 2015.

[5] B. A. McCarl and U. A. Schneider, "U.S. Agriculture's role in a greenhouse gas emission mitigation world: an economic perspective," Review of Agricultural Economics, vol. 22, no. 1, pp. 134-159, 2000.

[6] P. Smith, D. Martino, Z. Cai et al., "Greenhouse gas mitigation in agriculture," Philosophical Transactions of the Royal Society B: Biological Sciences, vol. 363, no. 1492, pp. 789-813, 2008.

[7] J. Antle and B. Mccarl, The Economics of Carbon Sequestration in Agricultural Soils, Oregon State University, Corvallis, OR, USA, 2003.

[8] B. A. McCarl, "Bioenergy in a greenhouse mitigating world," Choices, vol. 23, no. 1, 2008. 
[9] B. A. McCarl and U. A. Schneider, "Climate change: greenhouse gas mitigation in U.S. Agriculture and forestry," Science, vol. 294, no. 5551, pp. 2481-2482, 2001.

[10] CARB, "Proposed compliance offset protocol rice cultivation projects," October 2017, https://www.arb.ca.gov/cc/ capandtrade/protocols/riceprotocol.htm.

[11] N. Höhne, C. Warnecke, T. Day, and F. Röser, Carbon Market Mechanisms in Future International Cooperation on Climate Change, New Climate Institute, Cologne, Germany, October 2017, http://www.carbon-mechanisms.de/fileadmin/media/ dokumente/sonstige_downloads/NewClimate_2015_ Carbon_Market_Mechanisms_eng.pdf.

[12] E. Corbera, M. Estrada, and K. Brown, "How do regulated and voluntary carbon-offset schemes compare?" Journal of Integrative Environmental Sciences, vol. 6, no. 1, pp. 25-50, 2009.

[13] A. Millard-Ball, "The trouble with voluntary emissions trading: uncertainty and adverse selection in sectoral crediting programs," Journal of Environmental Economics and Management, vol. 65, no. 1, pp. 40-55, 2013.

[14] X. Liu and Q. Cui, "Baseline manipulation in voluntary carbon offset programs," Energy Policy, vol. 111, pp. 9-17, 2017.

[15] X. Liu and Q. Cui, "Value of performance baseline in voluntary carbon trading under uncertainty," Energy, vol. 145, pp. 468-476, 2018.

[16] G. C. van Kooten, T. N. Bogle, and F. P. de Vries, "Forest carbon offsets revisited: shedding light on darkwoods," Forest Science, vol. 61, no. 2, pp. 370-380, 2015.

[17] L. Schneider, "A Clean Development Mechanism with global atmospheric benefits for a post-2012 climate regime," International Environmental Agreements: Politics, Law and Economics, vol. 9, no. 2, pp. 95-111, 2009.

[18] A. M. Bento, R. Kanbur, and B. Leard, "Designing efficient markets for carbon offsets with distributional constraints," Journal of Environmental Economics and Management, vol. 70, pp. 51-71, 2015.

[19] B. C. Murray, B. A. McCarl, and H.-C. Lee, "Estimating leakage from forest carbon sequestration programs," Land Economics, vol. 80, no. 1, pp. 109-124, 2004.

[20] M. Lichtenfeld, "Improving the supply of carbon sequestration services in Panama," Journal of Sustainable Forestry, vol. 25, no. 1-2, pp. 43-73, 2007.

[21] M. Heller, "Chemical-resistant weeds sabotage no-till farming," E\&E News, https://www.eenews.net/stories/1063012625, February 2021.

[22] B. C. Murray, B. Sohngen, and M. T. Ross, "Economic consequences of consideration of permanence, leakage and additionality for soil carbon sequestration projects," Climatic Change, vol. 80, no. 1-2, pp. 127-143, 2007.

[23] P. J. Burke, "Undermined by adverse selection: Australia's direct action abatement subsidies," Economic Papers: A Journal of Applied Economics and Policy, vol. 35, no. 3, pp. 216-229, 2016.

[24] G. Chan, H. Bloomquist, B. Denk, and A. Hillstrom, "Guidelines for a sectoral sustainable development mechanism in the post-2020 climate regime," January 2021, http:// conservancy.umn.edu/handle/11299/190929.

[25] C. Fischer, "Project-based mechanisms for emissions reductions: balancing trade-offs with baselines," Energy Policy, vol. 33, no. 14, pp. 1807-1823, 2005.

[26] J. Strand and K. E. Rosendahl, "Global emissions effects of CDM projects with relative baselines," Resource and Energy Economics, vol. 34, no. 4, pp. 533-548, 2012.
[27] H. Wei, "Voluntary carbon market participation and unintended consequences: an economic analysis," Thesis, April 2018, http://oaktrust.library.tamu.edu/handle/1969.1/156992.

[28] P. H. G. Berkhout, J. C. Muskens, and J. W. Velthuijsen, "Defining the rebound effect," Energy Policy, vol. 28, no. 6-7, pp. 425-432, 2000.

[29] D. M. Adams, R. J. Alig, B. A. McCarl, and B. C. Murray, "FASOMGHG conceptual structure, and specification: documentation," March 2017, http://agecon2.tamu.edu/people/ faculty/mccarl-bruce/papers/1212FASOMGHG_doc.pdf.

[30] H.-C. Lee, B. A. McCarl, and D. Gillig, "The dynamic competitiveness of U.S. Agricultural and forest carbon sequestration," Canadian Journal of Agricultural Economics/Revue Canadienne d'agroeconomie, vol. 53, no. 4, pp. 343-357, 2005.

[31] R. H. Beach, D. M. Adams, R. J. Alig et al., Model Documentation for the Forest and Agricultural Sector Optimization Model with Greenhouse Gases (FASOMGHG), U.S Environmental Protection Agency, Washington, DC, USA, 2010.

[32] U. A. Schneider, "Agricultural Sector Analysis on Greenhouse Gas Emission Mitigation in the United States," Ph.D. thesis, Texas A\&M University, College Station, TX, USA, 2000.

[33] H. C. Lee, "The dynamic role for carbon sequestration by the US agricultural and forest sectors in greenhouse gas emission mitigation," Unpublished Ph.D. thesis, Department of Agricultural Economics, Texas A\&M University, College Station, TX, USA, 2002.

[34] B. A. McCarl and T. H. Spreen, "Price endogenous mathematical programming as a tool for sector analysis," American Journal of Agricultural Economics, vol. 62, no. 1, pp. 87-102, 1980.

[35] U. A. Schneider and B. A. McCarl, "Economic potential of biomass based fuels for greenhouse gas emission mitigation," Environmental and Resource Economics, vol. 24, no. 4, pp. 291-312, 2003.

[36] Forest Trends' Ecosystem Marketplace, Voluntary Carbon and the Post-Pandemic Recovery, State of Voluntary Carbon Markets Report, Special Climate Week NYC 2020 Installment, Forest Trends Association, Washington, DC, USA, 2020.

[37] N. Moreno, R. Moreno, and J. R. Molina, "Optimal harvest cycle on Nothofagus forests including carbon storage in Southern America: an application to Chilean subsidies in temperate forests," Land Use Policy, vol. 81, pp. 705-713, 2019.

[38] L. Elbakidze and B. A. McCarl, "Sequestration offsets versus direct emission reductions: consideration of environmental co-effects," Ecological Economics, vol. 60, no. 3, pp. 564-571, 2007.

[39] Y. Sapkota and J. R. White, "Carbon offset market methodologies applicable for coastal wetland restoration and conservation in the United States: a review," Science of The Total Environment, vol. 701, Article ID 134497, 2020.

[40] T. O. West and J. Six, "Considering the influence of sequestration duration and carbon saturation on estimates of soil carbon capacity," Climatic Change, vol. 80, no. 1-2, pp. 25-41, 2007.

[41] M.-K. Kim, B. A. McCarl, and B. C. Murray, "Permanence discounting for land-based carbon sequestration," Ecological Economics, vol. 64, no. 4, pp. 763-769, 2008.

[42] Z. Wang, M. Wlodarz, and B. McCarl, "Asset fixity and economic competitiveness of US ethanol production," Biomass and BIoenergy, vol. 122, pp. 37-44, 2019. 